\title{
Laboratory assays of the insecticidal activity of cyantraniliprole and imidacloprid on Brevicoryne brassicae, Myzus persicae (Hemiptera: Aphididae) and Trialeurodes vaporariorum (Hemiptera: Aleyrodidae) pests species and a biological control agent Chrysoperla defreitasi (Neuroptera: Chrysopidae)
}

\author{
M. Isabel Ahumada ${ }^{1}$, and Rodrigo A. Chorbadjian ${ }^{1 *}$ \\ 'Pontificia Universidad Católica de Chile, Facultad de Agronomía e Ingeniería Forestal, Vicuña Mackenna 4860, Santiago, Chile. \\ "Corresponding author (rchorba@uc.cl).
}

Received: 31 March 2019; Accepted: 3 July 2019; doi:10.4067/S0718-58392019000400658

\begin{abstract}
Cyantraniliprole has a broader insecticidal spectrum than the previously developed diamides. Because cyantraniliprole also targets hemipteran pests, it could provide an alternative to neonicotinoids like imidacloprid. However, there is limited information concerning how its broad-spectrum activity affects biological control agents. Toxicity of cyantraniliprole and imidacloprid to green peach aphid (Myzus persicae [Sulzer, 1776]), cabbage aphid (Brevicoryne brassicae [Linnaeus, 1758]) and greenhouse whitefly (Trialeurodes vaporariorum [Westwood, 1856]) nymphs was determined using both systemic and direct spray exposure. In addition, the direct spray activity of cyantraniliprole and imidacloprid on larvae of green lacewing, Chrysoperla defreitasi Brooks, 1994, was studied. Estimated $\mathrm{LC}_{50}$ values indicated that M. persicae, B. brassicae and T. vaporariorum were more susceptible to the systemic exposure to cyantraniliprole than to direct spray (0.148 vs. 24.284, 0.004 vs. 11.004 , and $0.268 v s .30 .832 \mathrm{mg} \mathrm{L}^{-1}$, respectively). Similarly, susceptibility of M. persicae, $B$. brassicae and T. vaporariorum to imidacloprid was more pronounced when exposed systemically than through direct contact ( $0.018 \mathrm{vs} .1 .149,0.006 \mathrm{vs} .0 .514$, and $0.249 \mathrm{vs} .6 .419 \mathrm{mg} \mathrm{L}^{-1}$, respectively). Hence, the population of $B$. brassicae was 40-fold more susceptible to cyantraniliprole than M.persicae when exposed to its systemic activity, and 2.2-fold more susceptible to cyantraniliprole's direct spray activity than M. persicae. Interestingly, T. vaporariorum was less susceptible to the direct spray activities of cyantraniliprole compared to that of imidacloprid by 4.8 -fold, but both insecticides were equally toxic for this species after systemic exposure. Crysoperla larvae were less susceptible to direct exposure to cyantranaliprole in comparison with imidacloprid (640.295 vs. $\left.26.974 \mathrm{mg} \mathrm{L}^{-1}\right)$. In comparison to imidacloprid, direct spray insecticidal activity of cyantraniliprole was less toxic to these hemipteran pests and to chrysoperla larvae. This suggests that the selectivity of cyantraniliprole towards $C$. defreitasi, as measured by direct spray only, could decline if its concentration is increased to target these hemipteran pests by foliar sprays.
\end{abstract}

Key words: Insecticide, lethal-concentration, Hemiptera, Neuroptera, selectivity. 


\section{INTRODUCTION}

The invention and development of insecticides with new target sites should provide alternatives to prevent insecticide resistance development while maintaining effectiveness to kill pests without affecting their natural enemies and other nontarget species. Because of pharmacophore differences amongst insect orders, the ryanodine receptor (RyR) is a promising pharmacological target for the development of new insecticides, that are target selective and with low mammalian toxicity (Qi and Casida, 2013; Qi et al., 2014; Casida, 2015). Diamide insecticides act as modulators of RyR, affecting the regulation of Ca release from inside the cell into the sarcoplasmic reticulum, which induces muscle contractions ending in paralysis (Sattelle et al., 2008). The first diamides, such as flubendiamide and chlorantraniliprole, were compounds with high selectivity for Lepidoptera (Jeanguenat, 2013). Later, cyantraniliprole was synthetized with a cyano group $(\mathrm{C} \equiv \mathrm{N})$ in the anthranilic core, replacing the chlorine atom of chlorantraniliprole. This substitution broadens the cyantraniliprole's control spectrum to include Lepidoptera, Hemiptera, Coleoptera and others (Caballero et al., 2013; Barry et al., 2015). The broad control spectrum of cyantraniliprole provides an alternative to previously available diamides (Barry et al., 2015). As such, cyantraniliprole use could replace the more selective chlorantraniliprole when hemipteran insects are attacking plants, yet information on its toxicity against piercing-sucking insects and its selectivity towards natural enemies is limited.

Piercing-sucking insects such as the green peach aphid Myzus persicae (Sulzer, 1776) (Hemiptera: Aphididae), the cabbage aphid Brevicoryne brassicae (Linnaeus, 1758) (Hemiptera: Aphididae) and the greenhouse whitefly Trialeurodes vaporariorum (Westwood, 1856) (Hemiptera: Aleyrodidae) are important pest species that damage and reduce the yield of various plants. These pests are difficult to control, and their ability to develop resistance to insecticides requires local investigation to advance and validate integrated pest management (IPM) strategies that are both consumer and environmentally friendly. In this study, M. persicae was tested because of their worldwide-recognized pest status in various vegetables, and their ability to develop resistance to existing insecticide molecules, including neonicotinoids, organophosphates, pyrethroids and carbamates (Criniti et al., 2008; Puinean et al., 2010; Silva et al., 2012; FuentesContreras et al., 2013). Brevicoryne brassicae (Linnaeus, 1758) (Hemiptera: Aphididae) and the greenhouse whitefly Trialeurodes vaporariorum (Westwood, 1856) (Hemiptera: Aleyrodidae) were selected as target species, because they are relevant pests affecting vegetable production in Chile (Klein-Koch and Waterhouse, 2000) and there is scarce information regarding the insecticidal activity of cyantraniliprole against these two insect species. For acute direct spray toxicity studies, the generalist biological control agent green lacewing Chrysoperla defreitasi Brooks, 1994 (Neuroptera: Chrysopidae) was included, for its potential to prey on a variety of pests and it is sold for biological control of pests on vegetable crops in Chile.

The objective of this study was to determine the susceptibility of M.persicae, B. brassicae and T. vaporariorum after systemic and direct spray exposure to cyantraniliprole and imidacloprid. In addition, we determined the $\mathrm{LC}_{50}$ values of both insecticides to $C$. defreitasi through direct spray exposure.

\section{MATERIALS AND METHODS}

\section{Insects and host plants}

Two aphid species, Myzus persicae (Sulzer, 1776) and Brevicoryne brassicae (Linnaeus, 1758) were collected from a local farm (Curacaví, Chile) and reared in separate cages containing cabbage plants for $1 \mathrm{yr}$ until experiments were conducted. The colony of Trialeurodes vaporariorum (Westwood, 1856) was started with adults collected in San Felipe (Chile) and reared on tomato plants maintained in cages. All colonies were maintained in a greenhouse at temperatures ranging $15-22{ }^{\circ} \mathrm{C}$ for 1 $\mathrm{yr}$, during which, several generations developed. Uninfested plants were provided weekly to maintain healthy colonies. No pesticides were used to maintain all insect colonies. Plants were watered as needed and fertilized weekly with water soluble nutrients (N:P:K 16:10:17).

Green lacewing eggs were obtained from BioBichos (Chillán, Chile), a commercial insectary that produces biocontrol agents. These Chrysoperla defreitasi (Brooks, 1994) eggs were allowed to hatch in the laboratory, and neonates were separated and reared in individual containers to prevent cannibalism. Chrysoperla defreitasi larvae were fed with aphids until they reached the third instar stage, at which point they were used for the direct spray toxicity bioassays. 


\section{Systemic insecticidal activity}

The systemic insecticidal activity of both cyantraniliprole (Azyra OD, DuPont de Nemours \& Co., Valdosta, Georgia, USA) and imidacloprid (Confidor 350 SC, Bayer CropScience AG, Monheim, Germany) was determined for M. persicae and $B$. brassicae on cabbage leaves and for T. vaporariorum on tomato leaves. These insecticide formulations were selected because of label recommendation for foliar spray. Each insecticide solution was added to a $20 \mathrm{~mL}$ vial into which the petiole of one leaf was inserted and fixed with parafilm (Bemis, Neenah, Wisconsin, USA). Insecticide solutions were prepared using distilled water. In cyantraniliprole bioassays, $M$. persicae was exposed to $0.1,0.14,0.18$ and $0.22 \mathrm{mg}$ $\mathrm{L}^{-1}$ active ingredient (ai), and B. brassicae was exposed to $0.003,0.0035,0.004$ and $0.0045 \mathrm{mg} \mathrm{L}^{-1}$ ai. For the bioassays with imidacloprid, M. persicae was exposed to $0.002,0.005,0.008,0.01,0.03$ and $0.05 \mathrm{mg} \mathrm{L}^{-1}$ ai, and B. brassicae was exposed to $0.0005,0.0008,0.002,0.006,0.01$ and $0.03 \mathrm{mg} \mathrm{L}^{-1}$ ai. Each concentration was tested in triplicate. For the control without insecticide, only distilled water was used. All aphids survived in the control treatments. All insecticide concentrations used were selected to encompass $50 \%$ mortality of target insects, based on preliminary assays.

Each leaf inserted in the vial carried a group of insects, obtained by infesting groups of 40-d-old plants with each insect species in separate rearing cages. For each aphid species, cabbage leaves $( \pm 10 \mathrm{~cm}$ long, $14 \mathrm{~d}$-old $)$ containing a small colony were removed and taken to the laboratory to eliminate excess adults, leaving a homogeneous group of $25 \pm 2$ nymphs in their first and second developmental stages per leaf. The exact nymphs' number was recorded for each experimental unit immediately before insecticide application. Whitefly adults were liberated in cages with tomato plants of three to four leaves to allow them to colonize the host. The adults were removed after $2 \mathrm{~d}$ of egg laying, and development continued for $2 \mathrm{wk}$ to allow the whitefly nymphs to reach $2^{\text {nd }}$ and $3^{\text {rd }}$ instars. Then, each plant was cut at the soil level and inserted in a vial with the insecticide treatment concentration. The initial number of whitefly nymphs per leaf was $17 \pm 4$. Bioassays with cyantraniliprole included concentrations of $0.01,0.05,0.08,0.1,0.3$ and $0.5 \mathrm{mg} \mathrm{L}^{-1}$ ai (plus control). Bioassays with imidacloprid included the following concentrations: $0.001,0.005,0.01,0.06,0.1$ and 0.5 $\mathrm{mg} \mathrm{L}^{-1}$ ai (plus control). All whiteflies survived in the control treatments with distilled water.

Each vial containing either one cabbage leaf or one small tomato cutting was placed inside a plastic cup (500 mL) and kept in place with a sponge. The cup was covered with a fine mesh to prevent the insects from escaping. To simulate greenhouse conditions, these experimental settings were maintained at $20^{\circ} \mathrm{C}$ until insect survival was evaluated. The aphids were counted and survival determined after $72 \mathrm{~h}$ (Foster et al., 2012), whereas the whitefly counts and survival were determined after $7 \mathrm{~d}$ (Sohrabi et al., 2011).

\section{Direct spray insecticidal activity}

Direct spray insecticidal activity of cyantraniliprole and imidacloprid was determined for M. persicae and B. brassicae on cabbage leaves, for $T$. vaporariorum on tomato leaves and for their natural enemy $C$. defreitasi on Petri dishes. One milliliter of insecticide solution was applied with a Potter tower (Burkard Scientific, Uxbridge, UK) directly onto aphids and nymphs of $T$. vaporariorum over the leaf and directly onto third instars of $C$. defreitasi. The same procedures previously explained in the systemic activity bioassays were made to prepare insecticide solutions and to prepare the leaves carrying a homogeneous group of aphid nymphs and first and second stage whitefly nymphs. For $C$. defreitasi, one third instar larva was placed into a Petri dish and sprayed with the Potter tower.

Myzus persicae was exposed to 15, 18,21, 24 and $27 \mathrm{mg} \mathrm{L}^{-1}$ ai cyantraniliprole, and to $0.1,0.5,0.75,1.0,1.5$ and 2.5 $\mathrm{mg} \mathrm{L}^{-1}$ ai imidacloprid. Brevicoryne brassicae was exposed to 5, 8.4, 8.8, 9.2, 11 and $15 \mathrm{mg} \mathrm{L}^{-1}$ ai cyantraniliprole, and to $0.01,0.05,0.1,0.5$ and $1.0 \mathrm{mg} \mathrm{L}^{-1}$ ai imidacloprid. Bioassays with $T$. vaporariorum included concentrations of $0.5,1.0$, 10,20 and $30 \mathrm{mg} \mathrm{L}^{-1}$ cyantraniliprole and $0.1,0.5,1.0,2.5$ and $5 \mathrm{mg} \mathrm{L}^{-1}$ imidacloprid. Only distilled water was used for the controls of each species. Insect survival was $98.9 \%, 100 \%$ and $100 \%$ in the control treatments with of M. persicae, $B$. brassicae and $T$. vaporariorum, respectively.

For the $C$. defreitasi bioassay with cyantraniliprole, ten replicates were tested for each of eight insecticide concentrations: $160,230,300,370,440,510,600,800$ and $1000 \mathrm{mg} \mathrm{L}^{-1}$ ai. For the imidacloprid bioassays, 10 replicates were tested at concentrations of $3,5,10,15,20,50,75$ and $100 \mathrm{mg} \mathrm{L}^{-1}$ ai. After each group of insects was sprayed, cabbage leaves and tomato cuttings were placed in water, and the vials were placed inside a mesh covered plastic cup. After spraying $C$. defreitasi, insects were put individually into plastic containers and fed with aphids regularly. Survival of $C$. defreitasi in the control treatment was $90 \%$. The exposed insects were maintained at $20^{\circ} \mathrm{C}$ until their survival was evaluated. Myzus 
persicae, B. brassicae and C. defreitasi survival was evaluated after $72 \mathrm{~h}$ (Foster et al., 2012), and T. vaporariorum survival was determined after $7 \mathrm{~d}$ (Sohrabi et al., 2011).

\section{Statistical analysis}

The assays were designed as completely randomized experiments with three replicates for each pest species and 10 replicates for $C$. defreitasi. Each group of insects sprayed was considered as an experimental unit. The $\mathrm{LC}_{50}$ values were calculated by standard Probit analysis (Buzzetti et al., 2016). Lethal concentrations were estimated from the regression between mortality levels using control-corrected data, transformed to Probit units by the logarithm of the concentration of insecticide, with a $95 \%$ confidence level.

\section{RESULTS}

The insecticidal activity of both cyantraniliprole and imidacloprid varied depending on the exposure route. Both active ingredients were more active on insect pests when applied systemically with lower insecticide concentrations needed to achieve $50 \%$ mortality on M.persicae, B. brassicae, and T. vaporariorum compared with direct spray activity (Table 1).

\section{Systemic insecticidal activity}

In systemic bioassays, regardless of the active ingredient, the order from highest to lowest susceptibility was $B$. brassicae, $M$. persicae and $T$. vaporariorum. Comparing cyantraniliprole with imidacloprid, both active ingredients had similar activity ( $\mathrm{LC}_{50}$ values) on both $T$. vaporariorum (0.268 vs. $0.249 \mathrm{mg} \mathrm{L}^{-1}$ cyantraniliprole and imidacloprid, respectively) and B. brassicae (0.004 vs. $0.006 \mathrm{mg} \mathrm{L}^{-1}$ cyantraniliprole and imidacloprid, respectively). However, M.persicae was more tolerant to cyantraniliprole than to imidacloprid when exposed systemically $\left(0.148\right.$ vs. $0.018 \mathrm{mg} \mathrm{L}^{-1}$ cyantraniliprole and imidacloprid, respectively) (Table 1).

\section{Direct spray insecticidal activity}

Regarding the relative activity of cyantraniliprole with respect to imidacloprid, higher concentrations of cyantraniliprole were required to cause the same effect as imidacloprid when pest insects were directly exposed to the insecticides. The $\mathrm{LC}_{50}$ values of cyantraniliprole for $M$. persicae, B. brassicae and T. vaporariorum were 24.284, 11.004 and $30.832 \mathrm{mg} \mathrm{L}^{-1}$, respectively, compared with the $\mathrm{LC}_{50}$ values of imidacloprid, which were 1.149 , 0.514 and $6.419 \mathrm{mg} \mathrm{L}^{-1}$, respectively (Table 1).

Table 1. Insecticidal activity of cyantraniliprole and imidacloprid on different insects.

\begin{tabular}{|c|c|c|c|c|c|}
\hline Species & Exposure & $\mathrm{n}^{\mathrm{a}}$ & Slope $\pm(\mathrm{SE})$ & $\mathrm{LC}_{50}\left(\mathrm{mg} \mathrm{L}^{-1}\right)(95 \% \mathrm{FL})^{\mathrm{b}}$ & $\mathrm{X}^{2}(\mathrm{df})$ \\
\hline \multicolumn{6}{|c|}{ Cyantraniliprole } \\
\hline \multirow[t]{2}{*}{ Myzus persicae } & Systemic & 416 & $39.0 \pm(4.7)$ & $0.148(0.138-0.158)$ & $6.2(2)$ \\
\hline & Direct spray & 422 & $2.6 \pm(0.8)$ & $24.284(20.892-28.227)$ & $15.7(3)$ \\
\hline \multirow[t]{2}{*}{ Brevicoryne brassicae } & Systemic & 435 & $1735.1 \pm(296.5)$ & $0.0037(0.0035-0.0039)$ & $17.4(2)$ \\
\hline & Direct spray & 549 & $2.9 \pm(0.5)$ & $11.004(9.907-12.222)$ & $2.3(5)$ \\
\hline \multirow[t]{2}{*}{ Trialeurodes vaporariorum } & Systemic & 391 & $12.0 \pm(1.3)$ & $0.268(0.225-0.311)$ & $0.5(4)$ \\
\hline & Direct spray & 302 & $0.6 \pm(0.2)$ & $30.832(11.524-79.898)$ & $5.0(3)$ \\
\hline Chrysoperla defreitasi & Direct spray & 100 & $2.1 \pm(0.6)$ & $640.295(424.9-964.5)$ & $15.2(7)$ \\
\hline \multicolumn{6}{|c|}{ Imidacloprid } \\
\hline \multirow[t]{2}{*}{ M.persicae } & Systemic & 570 & $3.0 \pm(0.4)$ & $0.018(0.015-0.021)$ & $53.9(4)$ \\
\hline & Direct spray & 570 & $87.5 \pm(9.1)$ & $1.149(0.962-1.355)$ & $45.5(4)$ \\
\hline \multirow[t]{2}{*}{ B. brassicae } & Systemic & 569 & $242.1 \pm(27.2)$ & $0.006(0.004-0.007)$ & $27.6(4)$ \\
\hline & Direct spray & 462 & $1.4 \pm(0.6)$ & $0.514(0.194-0.919)$ & $1.2(3)$ \\
\hline \multirow[t]{2}{*}{ T. vaporariorum } & Systemic & 334 & $5.7 \pm(1.4)$ & $0.249(0.140-0.369)$ & $13.4(4)$ \\
\hline & Direct spray & 299 & $1.6 \pm(0.4)$ & $6.419(3.144-12.283)$ & $6.7(3)$ \\
\hline C. defreitasi & Direct spray & 90 & $1.6 \pm(0.3)$ & $26.974(17.131-42.473)$ & $17.9(6)$ \\
\hline
\end{tabular}

Total number of insects tested (including controls).

${ }^{\mathrm{b}}$ Concentration resulting in $50 \%$ dead, with respective fiducial limits. 
The biological control agent $C$. defreitasi was less sensitive to cyantraniliprole as compared to imidacloprid, with an $\mathrm{LC}_{50}$ value of $640.295 \mathrm{mg} \mathrm{L}^{-1}$ for cyantraniliprole, whereas the $\mathrm{LC}_{50}$ of imidacloprid was $26.974 \mathrm{mg} \mathrm{L}^{-1}$.

\section{DISCUSSION}

In this study, a comparison between the direct spray and systemic activities of cyantraniliprole and those of imidacloprid, which was used as the commercial standard, is reported. The results obtained in this study are in concordance with previously reported $\mathrm{LC}_{50}$ values for the systemic activity of cyantraniliprole on M.persicae (Foster et al., 2012) and provide new data for its systemic activity on $B$. brassicae. Previously reported systemic activity $\left(\mathrm{LC}_{50}\right)$ of cyantraniliprole on the green peach aphid (M. persicae) ranges from 0.22 to $0.799 \mathrm{mg} \mathrm{L}^{-1}$ (Foster et al., 2012), which is similar to the $\mathrm{LC}_{50}$ value of $0.148 \mathrm{mg} \mathrm{L}^{-1}$ reported here. In addition, the population of B. brassicae tested was more susceptible to both insecticides. The lower susceptibility levels of $B$. brassicae were more pronounced when this species was exposed to the systemic activity of the insecticides compared to their direct spray effect. These results are useful as base-line susceptibility data for future assessment of potential insecticide resistance development. Comparing these data with previously reported $\mathrm{LC}_{50}$ 's suggests that these populations have not yet developed insecticide resistance to cyantraniliprole or imidacloprid in Chile, nevertheless it is important to evaluate their evolution to prevent potential control failures.

Information on insecticide susceptibility of the greenhouse whitefly (T.vaporariorum) is scarce, as most studies deal with the sweet potato whitefly, Bemisia tabaci (Gennadius, 1889). However, T. vaporariorum is the most important whitefly species in most areas of vegetable production in Chile, as the distribution of $B$. tabaci is restricted to a relatively small production area in the northern region of Chile (Klein-Koch and Waterhouse, 2000). As such, this study provides useful information to understand insecticide toxicity against this species. Other studies have investigated the systemic effects of cyantraniliprole on the sweet potato whitefly (B.tabaci) (Li et al., 2012; Caballero et al., 2013), with reported LC $_{50}$ values ranging between 0.015 and $0.042 \mathrm{mg} \mathrm{L}^{-1}$ for $B$. tabaci nymphs (Li et al., 2012). In contrast, direct spray exposure of the greenhouse whitefly (T. vaporariorum) to cyantraniliprole requires $9.8 \mathrm{mg} \mathrm{L}^{-1}$ ai to cause the same $\left(\mathrm{LC}_{50}\right.$ ) effect (Kumar and Singh, 2014). The results obtained in this study with the greenhouse whitefly $T$. vaporariorum show that the population tested here is three times more tolerant to direct spray exposure with cyantraniliprole than the results reported by Kumar and Singh (2014), and that it is ten times more tolerant to systemic exposure with cyantraniliprole compared with another whitefly species, B. tabaci (Li et al., 2012). Although we evaluated one population of T. vaporariorum, our results are in the high tolerance range of $T$. vaporariorum to cyantraniliprole previously reported (Moreno et al., 2018). Moreno et al. (2018) reported $\mathrm{LC}_{50}$ values between 0.017 and $0.194 \mathrm{mg} \mathrm{L}^{-1}$ using the same method of systemic exposure. The individuals used in this study were collected from an unmanaged area that is not far away from commercial greenhouses where insecticides are intensively used; thus, it is likely that some level of insecticide tolerance has developed in this population.

Overall, the activity of both cyantraniliprole and imidacloprid was higher when applied systemically than in direct spray activity because lower concentrations of active ingredient were needed to cause the same effect when insects ingested the insecticides. However, species-specific differences were detected when comparing the lethal effects of these insecticides for each pest species within each exposure route. Myzus persicae was more susceptible to imidacloprid than to cyantraniliprole after both direct spray and systemic exposure. However, B. brassicae and T. vaporariorum were more susceptible to imidacloprid than to cyantraniliprole only in the direct spray exposure. This difference was not detected when both insecticides were applied systemically. Therefore, in this study the activity of cyantraniliprole was more similar to that of imidacloprid when applied systemically than through direct spraying.

The green lacewing $(C$. defreitasi) is a generalist biological control agent that feeds on aphids, whiteflies and other small insects. In this study, we found that Chrysoperla is more tolerant to direct exposure to both imidacloprid and cyantraniliprole than either aphid species (B. brassicae and M.persicae) or the greenhouse whitefly T. vaporariorum. Our results with $C$. defreitasi larvae indicate an $\mathrm{LC}_{50}$ of $640.295 \mathrm{mg} \mathrm{L}^{-1}$ for cyantraniliprole, which conforms with previous information showing that $160 \mathrm{mg} \mathrm{L}^{-1}$ produced nonsignificant mortality of other Chrysoperla species, i.e. C. carnea (Stephens, 1836) and C. johnsoni Henry, Wells and Pupedis, 1993 (Amarasekare and Shearer, 2013). Amarasekare and Shearer (2013) also report that sub-lethal exposure to cyantraniliprole extended the developmental period of Chrysoperla larvae. Although, integrated pest management strategies aimed to protect natural enemies could benefit when considering the relative direct spray activities of insecticide molecules rather than their insecticidal activities in isolation, ingestion exposure of the natural enemy and sub-lethal effects should be also considered in future studies. 


\section{CONCLUSIONS}

Both imidacloprid and cyantraniliprole were more active on Myzus persicae, Brevicoryne brassicae and Trialeurodes vaporariorum through systemic application compared to direct spraying. In general, more of the active ingredient of cyantraniliprole was needed than of imidacloprid to cause the same effect, except for the systemic application directed to $B$. brassicae and T. vaporariorum. In comparison with imidacloprid, the direct insecticidal activity of cyantraniliprole was less toxic for M. persicae, B. brassicae, T. vaporariorum and Chrysoperla defreitasi.

\section{REFERENCES}

Amarasekare, K.G., and Shearer, P.W. 2013. Comparing effects of insecticides on two green lacewings species, Chrysoperla johnsoni and Chrysoperla carnea (Neuroptera: Chrysopidae). Journal of Economic Entomology 106(3):1126-1133.

Barry, J.D., Portillo, H.E., Annan, I.B., Cameron, R.A., Clagg, D.G., Dietrich, R.F., et al. 2015. Movement of cyantraniliprole in plants after foliar applications and its impact on the control of sucking and chewing insects. Pest Management Science 71:395-403.

Buzzetti, K., Chorbadjian, R.A., Fuentes-Contreras, E., Gutiérrez, M., Ríos, J.C., and Nauen, R. 2016. Monitoring and mechanisms of organophosphate resistance in San Jose scale, Diaspidiotus perniciosus (Hemiptera: Diaspididae). Journal of Applied Entomology 140(7):507-516.

Caballero, R.R., Cyman, S.S., Schuster, D.J., Portillo, H.E., and Slater, R.R. 2013. Baseline susceptibility of Bemisia tabaci (Genn.) biotype B in southern Florida to cyantraniliprole. Crop Protection 44:104-108.

Casida, J.E. 2015. Golden age of RyR and GABA-R diamide and isoxazoline insecticides: common genesis, serendipity, surprises, selectivity, and safety. Chemical Research in Toxicology 28:560-566.

Criniti,A.A., Mazzoni, E.E., Cassanelli, S.S., Cravedi, P.P., Tondelli, A.A., Bizzaro, D.D., et al. 2008. Biochemical and molecular diagnosis of insecticide resistance conferred by esterase, MACE, $k d r$ and super- $k d r$ based mechanisms in Italian strains of the peach potato aphid, Myzus persicae (Sulzer). Pesticide Biochemistry and Physiology 90(3):168-174.

Foster, S.P., Denholm, I.I., Rison, J.L., Portillo, H.E., Margaritopoulis, J.J., and Slater, R.R. 2012. Susceptibility of standard clones and European field populations of the green peach aphid, Myzus persicae, and the cotton aphid, Aphis gossypii (Hemiptera: Aphididae), to the novel anthranilic diamide insecticide cyantraniliprole. Pest Management Science 68:629-633.

Fuentes-Contreras, E.E., Figueroa, C.C., Silva, A.X., Bacigalupe, L.D., Briones, L.M., Foster, S.P., et al. 2013. Survey of resistance to four insecticides and their associated mechanisms in different genotypes of the green peach aphid (Hemiptera: Aphididae) from Chile. Journal of Economic Entomology 106:400-407.

Jeanguenat, A.A. 2013. The story of a new insecticidal chemistry class: the diamides. Pest Management Science 69:7-14.

Klein-Koch, C., and Waterhouse, D.F. 2000. The distribution and importance of arthropods associated with agriculture and forestry in Chile. ACIAR Monograph Series Nr 68. 234 p. Australian Centre for International Agricultural Research (ACIAR), Canberra, Australia.

Kumar, A., and Singh, R. 2014. Bioefficacy of some insecticides against the greenhouse whitefly Trialeurodes vaporariorum, Westwood (Homoptera: Aleyrodidae) on tomoto. The Bioscan 9(3):1073-1076.

Li, X.C., Degain, B.A., Harpold, V.S., Marçon, P.G., Nichols, R.L., Fournier, A.J., et al. 2012. Baseline susceptibilities of B- and Q-biotype Bemisia tabaci to anthranilic diamides in Arizona. Pest Management Science 68:83-91.

Moreno, I., Belando, A., Grávalos, C., and Bielza, P. 2018. Baseline susceptibility of Mediterranean strains of Trialeurodes vaporariorum (Westwood) to cyantraniliprole. Pest Management Science 74(7):1552-1557.

Puinean, A.M., Foster, S.P., Oliphant, L., Denholm, I., Field, L.M., Millar, N.S., et al. 2010. Amplification of a cytochrome P450 gene is associated with resistance to neonicotinoid insecticides in the aphid Myzus persicae. PLoS Genetics 6(6):e1000999.

Qi, S., and Casida, J.E. 2013. Species differences in chlorantraniliprole and flubendiamide insecticide binding sites in the ryanodine receptor. Pesticide Biochemistry and Physiology 107(3):321-326.

Qi, S., Lümmen, P., Nauen, R., and Casida, J.E. 2014. Diamide insecticide target site specificity in the Heliothis and Musca ryanodine receptors relative to toxicity. Journal of Agricultural and Food Chemistry 62(18):4077-4082.

Sattelle, D.B., Cordova, D., and Cheek, T.R. 2008. Insect ryanodine receptors: molecular targets for novel pest control chemicals. Invertebrate Neuroscience 8:107-119.

Silva, A.X., Jander, G.G., Samaniego, H.H., Ramsey, J.S., and Figueroa, C.C. 2012. Insecticide resistance mechanisms in the green peach aphid Myzus persicae (Hemiptera: Aphididae) I: a transcriptomic survey. PLOS ONE 7(6):e36366.

Sohrabi, F., Shishehbor, P., Saber, M., and Mosaddegh, M.S. 2011. Lethal and sublethal effects of buprofezin and imidacloprid on Bemisia tabaci (Hemiptera: Aleyrodidae). Crop Protection 30:1190-1195. 